\title{
Analysis of Identity of Banks in Bosnia and Herzegovina by Using ACID Test
}

\author{
Ermina Smajlović ${ }^{1}$ \\ ${ }^{1}$ Faculty of Economics, University of Tuzla, Bosnia and Herzegovina \\ Correspondence: Ermina Smajlović, Faculty of Economics, University of Tuzla, Univerzitetska 8, 75000 Tuzla, \\ Bosnia and Herzegovina. Tel: 38-761-725-984. E-mail: ermina.mustafic@ untz.ba
}

Received: June 2, 2014

Accepted: June 28, 2014

Online Published: July 25, 2014

doi:10.5539/ibr.v7n8p17

URL: http://dx.doi.org/10.5539/ibr.v7n8p17

\begin{abstract}
In order to keep the present and attract the new clients, banks need to be clearly positioned on the market, and they can do this through the creation of identity. In the modern literature in the area of bank marketing, the identity is defined more and more as an effective tool for banks to gain competitive advantage. The unique identity of a bank represents competitive advantage that is impossible to copy. This is highly significant for banks, since bank services have a short cycle of development that cannot be patented, and this enables the competition to simply imitate the innovations and create similar offers. This paper analyses bank identity in Bosnia and Herzegovina applying the ACID test used to manage corporate identity. The application of the ACID test contains three basic phases, that is: to determine the actual, communicated, ideal, and desired identity; to determine the relation between those identities; and to diagnose actions that need to be taken in order to minimize their non-consistency. According to the research results, it can be concluded that there are significant deviations between the actual, communicated, ideal and desired identity of banks on the market of Bosnia and Herzegovina, which is a consequence of the lack of systemic approach to manage this phenomenon. Therefore, suggestions are given on how to remove, that is, to minimize non-consistency between the four named identities.
\end{abstract}

Keywords: ACID test, bank identity in Bosnia and Herzegovina

\section{Introduction}

The modern conditions of bank operations are determined by numerous changes in the marketing environment. The successful approach on the market is additionally made difficult by strong competition, that is, by strong attack of foreign banks on domestic markets that is caused by globalization. The fast development of information-communication technologies enables clients a simple access to financial services data, and this affects their opinions when assessing quality of banking offers, and their much lower level of loyalty. The consequence of this is that clients more often are in a position to terminate business with their bank if they are not satisfied with its operations.

In order to keep the present and attract the new clients, banks need to be clearly positioned on the market, and they can do this through the creation of identity. In the modern literature in the area of bank marketing, the identity is defined more and more as an effective tool for banks to gain competitive advantage. Clearly profiled bank identity, as well as its strong image, will differentiate the bank from its competition, and put it in a clear position on a target market. The unique identity of a bank represents competitive advantage that is impossible to copy. This is highly significant for banks, since bank services have a short cycle of development that cannot be patented, and this enables the competition to simply imitate the innovations and create similar offers. The effective identity reflects norms and values that are fundamental to bank operations, and this determines the character and the emotional strength of their offer. In order for the bank identity to function properly, it needs to be reflected in the exterior and interior design, appearance, and staff behavior, symbols, events, that is, it needs to be reflected in all instruments and media the bank uses to communicate with its surroundings. This way assures that banks can differentiate from the competition, and therefore gain loyalty of present clients as well as attract new clients, who do not assess service prices only, but also who asses various other aspects of banking services in the process of buying such.

According to the above mentioned, this paper will present the concept of bank identity, the way bank identity is analyzed by application of ACID test, and it will present the research results of bank identities in Bosnia and 


\section{Herzegovina (B\&H).}

\section{Conceptual Determination of Bank Identity}

A large number of authors have conducted researches on the topic of corporate identity. Therefore, literature in this scientific field contains numerous determinations of this phenomenon. Since corporate identity is defined within the frames of different theories, its numerous determinations do not lead to enlightenment of this phenomenon, but they rather create even larger confusion. Still, identity definition can be made through their analysis, in which the relationship is made with the corporate personality or character that evolved into a more complex form in time and this form lies in the multidisciplinary approach.

Corporate personality covers the subject in the deepest way. It is the soul, the persona, the spirit, the culture of the organization that is manifested in some way. Corporate personality is not necessarily something tangible, something that can be seen, felt, or touched - although it could be. The tangible manifestation of corporate personality is the corporate identity. The identity is the one who projects and reflect the reality of corporate personality (Olins, 1978, according to Cornelissen \& Harris, 2001).

Corporate identity is a term that is most often used to determine a program of communication and change that a company needs to take along with its external consultant. In fact, this term describes itself in the most precise manner. Identity of an organization is comprehension on one self - very similar to our comprehension of our own identity. Therefore, identity is unique. Identity of an organization consists of its history, beliefs and philosophies, its nature of technology, its property, people, management personalities, its ethical and cultural value, and its strategy (Ind, 1996). Identity includes the ways in which a company wishes to identify itself or in which it wishes to position its product (Kotler, 2001).

Some authors feel that there are differences between definitions of corporate identity, made by theoreticians and practitioners. This way, Melewar and Jenkins accent that the definitions of practitioners are more focused on the visible aspects of identity, which are easily managed. As an example, they present the definition of corporate identity in which the identity is determined as presentation of an organization towards its various stakeholders and way to differentiate its own organization from all other organizations (Marwick \& Fill, 1997, according to Melewar \& Jenkins, 2002). The focus on the significance of corporate identity in business practices, and the role significance plays in the determination of its definition can be recognized in the works of German authors, Birkigt and Stadler (Note 1), as well.

Through the analysis of mentioned definitions of corporate definition, the following observation can be made:

$>$ There isn't a unitary attitude toward corporate identity.

$>$ Authors define corporate identity according to their own goals and theoretical assumptions.

$>$ Common variables of identity definitions: personality, way to present, behavior, communication, etc., can be recognized.

It is important to mention the strategic significance of identity that enables differentiation from the competition and through that, it enables realization of competitive advantage which is hard to imitate. According to the previous analysis of definitions of corporate identity and adopted assumptions, the following conceptual determination of bank identity can be made.

Bank identity is an assembly of specific, interrelated characteristics, determined by culture and business orientation, presented to the internal and external public, through communication, behavior and design.

An effective identity reflects norms and values that business operations are founded on, and this determines character and emotional strength of their offer. In order for the bank identity to function properly, it needs to be reflected in the exterior and interior design, appearance, and staff behavior, symbols, events, that is, it needs to be reflected in all instruments and media the bank uses to communicate with its surroundings. Only through permanent placement of chosen message for the public, can a bank affect the perception of its clients, that is, create a wanted bank image.

\section{Basic Theoretical ACID Test Settings}

For systemic analysis of bank identities, it is necessary, before all, to determine an adequate approach to their research in analysis. Especially in this aspect of managing identity, many researches have been conducted by eminent scientific and consulting individuals in this field. One of the most recent accomplishments in this research field is the ACID Test of Corporate Identity Management (Figure 1), developed by Balmer and Soenen in 1999. 


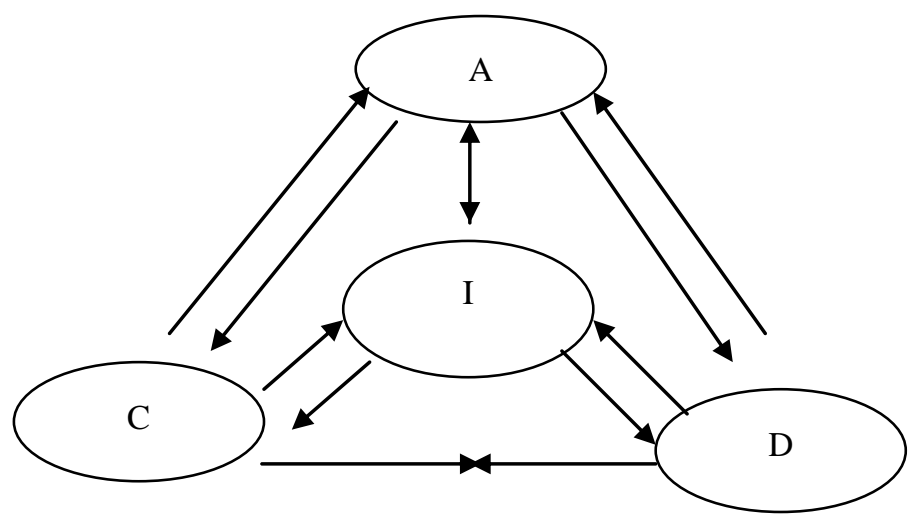

Figure 1. ACID Test of corporate identity management ${ }^{\mathrm{TM}}$ (Fox, Balmer \& Wilson 2001)

The approach to development of this method was strategic and multidisciplinary, instead of the traditional approach to corporate identity as a discipline whose basic communication is based on graphic design. There are four types of identities distinguished in the ACID Test: actual, communicated, ideal and desired. These differences are made in accordance with the complex structure of corporate identity, and they have to be taken into account by managers in the stages of its planning and analysis. They are defined in the following way (Fox, Balmer \& Wilson 2008):

$>$ Actual Identity: what is an organization;

$>$ Communicated Identity: how is an organization perceived by public, and how is an organization communicating;

$>$ Ideal Identity: optimal positioning of an organization on the market;

$>$ Desired Identity: identity that is tried to be developed by the executive manager or the board of directors.

The application of the ACID Test takes places in the process with three basic phases, that is: 1) to determine four different identities, 2) to determine the relation between those identities, and finally 3 ) to diagnose actions that need to be taken in order to minimize their non-consistency. It is anticipated that these stages have to be "followed by managers and consultants in order to recognize necessary changes and to risk what is urgent, important, and what is simply desired". Table 1 presents research areas and techniques used to collect data, as suggested by Balmer and Soenen in the frame of this model.

Table 1. Presentation of chosen methods in ACID test application (Fox, Balmer \& Wilson 2001)

\begin{tabular}{cll}
\hline Identities & \multicolumn{1}{c}{ Identity Elements that Need to be Researched } & Suggested Techniques for Data Collection \\
\hline Actual Identity & Internal values & Structured survey \\
& Service characteristics & Internal semi-structured interview \\
& History & External semi-structured interview \\
& Structure & \\
& Management style & \\
Communicated & Corporation reputation at different stakeholder groups & Assessment of visual communications \\
Identity & Total corporation communication (marketing management, & Internal semi-structured interview \\
& organization communication, and non-controllable communication, & External semi-structured interview \\
& ie. Staff behavior, press comments & Media coverage analysis (local and national) \\
& Visual identity & \\
& Strengths and possibilities & Strategic analysis of the company and the \\
& Optimal corporation position & branch it belongs to: \\
& Optimal corporation values and philosophy & SWOT analysis \\
& Optimal product and service characteristics & PEST analysis \\
& Optimal organizational structure & Analysis of statements of external market \\
& Optimal market coverage & research \\
& Optimal corporate behavior & Analysis of internal strategic documents \\
& Trends in surroundings & Internal semi-structured interview \\
& Top management's vision & Analysis of internal communication and \\
& Founders and most important shareholders' vision & strategic documents \\
\hline \multirow{2}{*}{ Desired Identity } & Other stakeholder groups' vision &
\end{tabular}


The research on mentioned operation aspects would be the first step in the determination of bank identities with the application of ACID Test. In the scope of the analysis of the actual bank identity, its fundamental values would be determined, the values that differentiate it from the competition. The communicated identity would show the communications approach of banks with their internal and external surroundings. The ideal identity would determine the optimal position of banks in regards to their competition, while the top management and the board of directors would provide their vision of the desired identity (Note 2).

The second step should determine interaction between set identities, as shown in Figure 2.

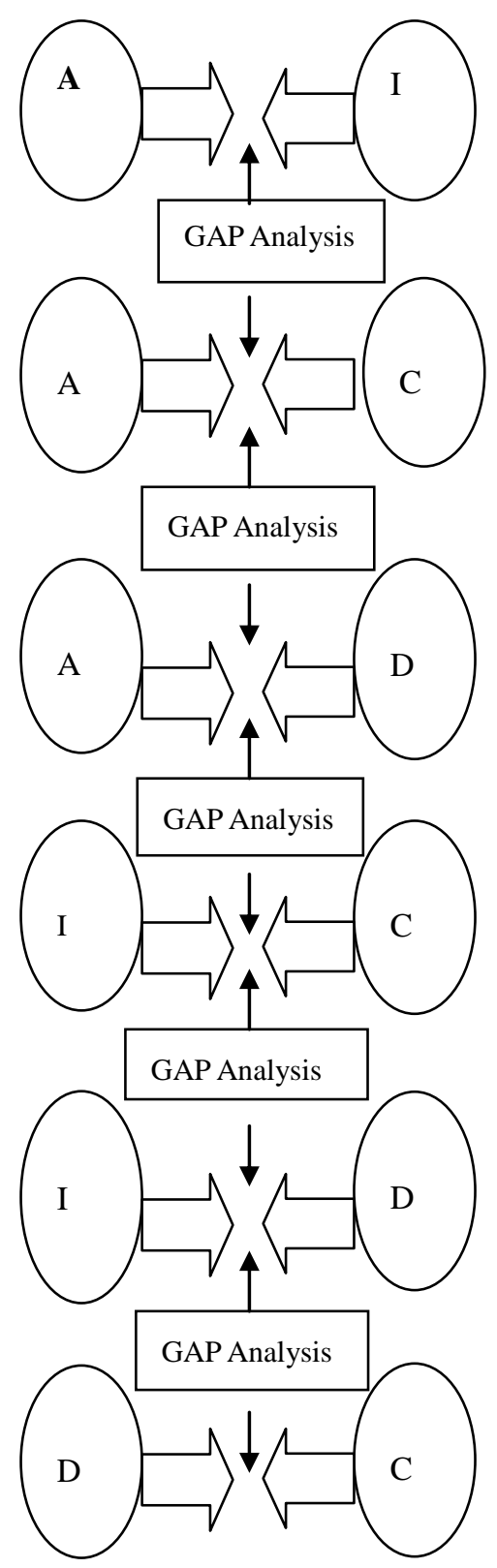

Is the organization position optimal? Is it ideally reflected through internal values, products and services, market coverage, management politics?

Does organization communication properly represent the organization the way it really is? Does corporation reputation reflect organization reality? Do third parties (ie. Press) give true value to the organization?

Does organization reality actually reflect top management's vision?

What level of ideal positioning is possible in accordance with the reputation of organization, branch and state? To what level can the current reputation be improved?

Are the corporation mission and management vision strategically aligned, and are company capacities and market possibilities entirely used?

Are the corporate mission and management vision in effective communication, both externally and internally? Are the corporate reputation and the total corporate communication politics aligned with the management vision?

\section{$\mathrm{A}=$ actual identity $\mathrm{C}=$ communicated identity $\mathrm{I}=$ ideal identity $\mathrm{D}=$ desired identity}

Figure 2. Red ACID test process (Fox, Balmer \& Wilson 2001)

According to the presented above, banks should determine six interactions between set identities. Through the 
interaction of the actual and the ideal identities of banks, the level of current position deviation from the ideal position could be determined; the relation between the actual and the communicated identities of banks would determine the efficiency of bank communications; and by comparison of the actual and the desired identities of banks, the level of current position deviation and the top management's vision could be determined. Interaction of the ideal and the communicated identities of banks would determine possible ideal position on a certain banking market, and relation between the ideal and the communicated identities, and the ideal and desired identities of banks would point in the direction of possible unused capacities and possibilities. Interaction between the communicated and the desired identities of banks would determine the level of deviation between top management's vision and total bank communications. According to the results gained by application of the ACID Test, banks could develop and implement strategies that would enable them to minimize deviations at certain levels, and with that, create the desired identity.

Recognition and analysis of different bank identities requires multidisciplinary approach to the research issue as shown in Table 1. According to the Table, it can be determined that Balmer starts from the assumption that different identities need to be observed in different time frames, as each one of them undergoes special management field. In accordance with this attitude, bank identities need to be observed in present, where their analysis should be related to bank operation strategies, organization cultures and structures, styles of leadership and management of bank communications. The communicated identity of banks should be observed in all three time frames. The way secondary bank communications were managed in past, determines present communicated identity, as the controlled communications in present determine the future communicated identity. Opposite to that, primary communication of banks with its surroundings through the 7P's directly reflects the present communicated identity. In the scope of the precipitated identity, banks should analyze the way their image and brand management in past reflected on the client perception in the present. The ideal identity banks can realize in the future by creation and implementation of adequate marketing strategies that would enable them to use all the existing chances in their surroundings. The desired identity represents the vision of the bank leaders who will strive to realize it in the future.

\section{Analysis of Research Results on Bank Identities in Bosnia and Herzegovina}

\subsection{Methodological Basis of Conducted Research}

In the past fifteen years, banks in B\&H have faced numerous changes in operations. By the end of the war, the economy of $\mathrm{B} \& \mathrm{H}$ found itself in the process of transition and privatization, and banks had to make additional efforts to adapt to operations in the conditions of the finalized process of privatization of the banking sector and the deregulation of economic activities. On the banking market in B\&H, many significant changes took place that can be seen also in the consequences of globalization, that is, in the emerging nature of significant number of foreign banks, which resulted in the strong competition in the frame of this sector. In such conditions, banks need to develop strong competitive advantages that would enable them market growth and operations stability. In the scope of analysis of the banking market in $\mathrm{B} \& \mathrm{H}$, it is necessary to emphasized that it is divided into Federation of Bosnia and Herzegovina (F B\&H) and the Republic of Srpska (RS), and also that these two entities do not undergo the same legal regulations. Therefore, two regulatory agencies are formed that supervise bank operations in FB\&H and RS. With this in mind, bank operations in B\&H are territorially limited to one of the entities. According to that, certain number of banks that operate in both entities had to form sister banks such as: Volksbank BH and Volksbank a.d. Banja Luka or Hypo Alpe-Adria-Bank d.d Mostar and Hypo Alpe-Adria-Bank a.d. Banja Luka. Besides the geographical segmentation, the banking market can be segmented into markets of final and operation demand. The market of final demand is most often segmented on the basis of demographic and socio-economic characteristics, such as: age, level of education, personal income, and such. With this, banks usually form certain client groups that can use their services in special conditions. This privileged position can be experienced employees of public authorities, as well as employees of larger companies who have special business arrangements with banks. On the side of operation demand, there are micro, small, medium and large companies and public authorities and institutions. Having this in mind, banks have to execute market segmentation in order to create marketing program that will fit their clients' needs.

This research has formed an attitude that in the conditions of dynamic environment and sharper competition on banking market, banks need to build sustainable competitive advantages. Since specifics of banking services determine complexity of their differentiation, only through identity management can banks achieve the competitive advantage. By creating and sustaining strong identities, banks are clearly differentiated from the competition and are clearly positioned on the market. The basic advantage of bank identity is their uniqueness, that is, impossibility to copy. 
Issues associated with bank identity research can be seen in the following:

$>$ Bank identity can be seen from various perspectives through various time dimensions:

$>$ Complexity of bank identity requires multidisciplinary approach to research;

$>$ Identity is multidimensional, that is, it is made up of numerous qualitative and quantitative characteristic, and this highly affects the complexity of its research;

$>$ Complexity of research is increased with the increase of the number of observed banks;

The presented issues of research show us the scope and the complexity of research of bank identities. To conduct this research of bank identity in its full form taking into consideration (almost) all its aspects, would overcome our framework, therefore, we decided to limit our research. The limits of the research are seen in the following:

$>$ Research will be conducted on the area of $\mathrm{B} \& \mathrm{H}$;

$>$ Bank managers and staff will represent the segment of internal public.

We assume that the research, conducted with mentioned limitations, can shed light on relevant aspects of management of actual, communicated, desired and ideal identities of banks in B\&H. As sources of information required for this research, we used secondary data, that is, publications and bank statements, bank web-pages, and primary data collected through conducted surveys.

The targeted group of this research consists of top managers of banks across B\&H. On Central Bank's homepage (www.cbbh.ba), banks that operate in B\&H are listed. In 2009, when this research was conducted, there were 19 banks operating in FB\&H and 10 banks operating in RS. After that, we used these banks' homepages to gather information such as: addresses, phone numbers, webmail, and names of top managers of banks across B\&H. Data was collected with a help of a survey that was sent out to top managers by e-mail. Data collected from the surveys was compared to data published on the banks' homepages. 22 managers were surveyed in total, which represents $75.86 \%$ of the total number in $\mathrm{B} \& \mathrm{H}$.

For data analysis, collected through research, the following statistical scientific methods were used:

$>$ Descriptive statistical analysis of collected data;

$>$ Descriptive analysis of chosen data interrelation;

The analyzed results of the conducted research on bank identities on $\mathrm{B} \& \mathrm{H}$ market will be presented in the following paragraphs.

\subsection{Results Gathered through the Application of ACID Test in the Process of B\&H Bank Identity Research}

Starting from the Balmer division of identities into actual, communicated, ideal and desired, in the framework of our research, we tried to establish their existence in banks that operate on B\&H market. In the scope of research of actual identity, we researched the operations history of banks on B\&H banking market, the basic values of bank operations, and their integration into mission and vision, their basic characteristics upon they differentiate from the competition, and manager's attitude on the most important criteria that makes clients choose a particular bank to do their business with. Communicated identity represents a way in which banks present their personality to their surroundings. According to the presented above, this segment of research was focused on determination of instruments and media of bank communication with its surroundings. Through that, we tried to determine the size of attention that banks give to their audio-visual characteristics of identity, such as: logo, colors, architectural solutions and slogans, and development of the bank brand. The way it is communicated with staff, and the way of motivating the staff was additionally researched. In the scope of research of communication of banks with their external surroundings, we tried to determine which media were used, do they present themselves as sponsors, and if they research the effects of their communication. Through the research of ideal identity, we tried to determine if banks have set marketing strategies, and if they follow competition operations and client satisfaction. Desired identity represents a way in which banks desire to be precipitated in their surrounding, their desired positions on the market, and their desires toward certain market participation. Therefore, in this part of our research, we tried to determine bank desires in the named characteristics of operations.

\section{Actual Identity of Banks}

Having in mind that $\mathrm{B} \& \mathrm{H}$ is a country in transition, it is not surprising that banks went through numerous significant status changes, such as mergers with one or more banks, or takeovers by some other banks. Therefore, on banking market of $\mathrm{B} \& \mathrm{H}$, banks that dominate are the ones who are operating in a very short time in our country. The analysis of bank operation traditions in FB\&H showed that $80 \%$ of banks went through final status 
changes in the period from 1999 to 2009.

When we researched the written documents of banks, presented on their official web-sites, we could determine that only $22.22 \%$ of banks defined their operations mission, while $14.81 \%$ of banks defined their vision. With that, the basic values that are integrated into bank vision were: improvement of operations quality, client focus, and contribution to the economic development of the country. In their visions, banks, before all, determined their anticipation to: satisfy clients' needs, and become modern banks among the leading banks in B\&H. When we researched management style in banks, we gathered that $83.33 \%$ are team managers, while $16.66 \%$ belong to the medium management group. On the basis of gathered answers from the bank managers, it could be concluded that all the surveyed banks are anticipating entrepreneurial behavior, having in mind that $41.66 \%$ of banks have a more emphasized entrepreneurial organizational structure, while $45 \%$ of banks still have very emphasized bureaucratic organizational elements. Bank managers provided us with numerous various values that characterize the operations of their banks. The gathered values can be grouped into the following: quality staff (41.66\%), loyalty (33.33\%), security (33.33\%), individual client approach (33.33\%), tradition (33.33\%), social responsibility (25\%), and the application of new technologies (16.66\%), and service quality (16.66).

Managers provided us with various characteristics that make their banks differentiate from the competition. Having in mind the large number and the variety of gathered characteristic, and the fact that they are ranked up to the fifth level, in this part, we will limit our focus on the mostly named characteristics (Figure 3.). Therefore, the most important or the first-ranked characteristics that managers listed were: security $16.66 \%$, client proximity $16.66 \%$, assortment quality $8.33 \%$, staff quality $8.33 \%$, and loyalty $8.33 \%$. The most listed second-ranked characteristics of differentiation were: expeditivity $23.07 \%$, assortment quality $16.38 \%$, staff quality $8.33 \%$, loyalty $8.33 \%$, security $7.69 \%$, client proximity $7.69 \%$, and bank brand $7.69 \%$. The third-ranked characteristics of differentiation were: bank brand 25\%, assortment quality $16.66 \%$, expeditivity $8.33 \%$, staff quality $8.33 \%$, security $8.33 \%$, and client proximity $8.33 \%$.

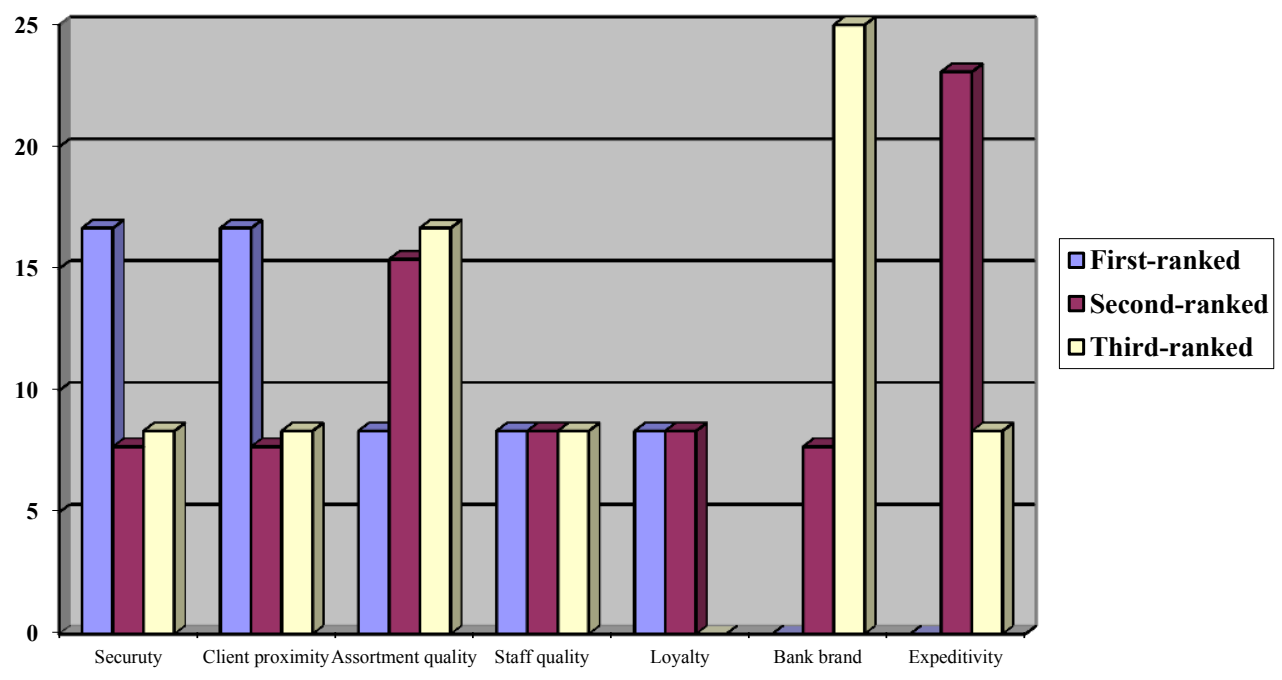

Figure 3. Basic characteristics on which banks differentiate from competition (Smajlović 2010)

Communicated identity represents a way in which banks present their personality to their surroundings. This segment of research was focused on determination of instruments and media of bank communication with its surroundings. Here, we tried to figure out the size of attention that banks give to audio-visual characteristics of their identity, such as: logo, colors, architectural solutions and slogans, and development of the bank brand. We additionally researched communication style with employees, and ways in which employees are motivated. In the scope of research on how banks communicate with their external surroundings, we tried to determine which media they use, if they play sponsor roles, and if they research the effects of their communication.

The research on management and motivation of staff has shown that all managers have an appropriate approach where the staff is introduced to their tasks and operation goals, as well as with criteria of the evaluation of their performance, and promotion conditions. But, it has been noticed that there is inadequacy in staff cash reward $(41.66 \%)$ which usually negatively affects staff motivation to show extraordinary results in the scope of their 
operations. During the secondary research of bank web-sites, we concluded that $66.66 \%$ of banks have their slogan, while $88.88 \%$ of banks have clearly recognizable colors, while $96.29 \%$ of banks have their own logo. When constructing their offices and branches, banks especially emphasize modern design (83.33\%), and adaption of their exterior and interior colors to the bank colors $(83.33 \%)$. Besides that, banks try to emphasize an open approach (66.66\%), and to protect the discretion of their operations $(50 \%)$.

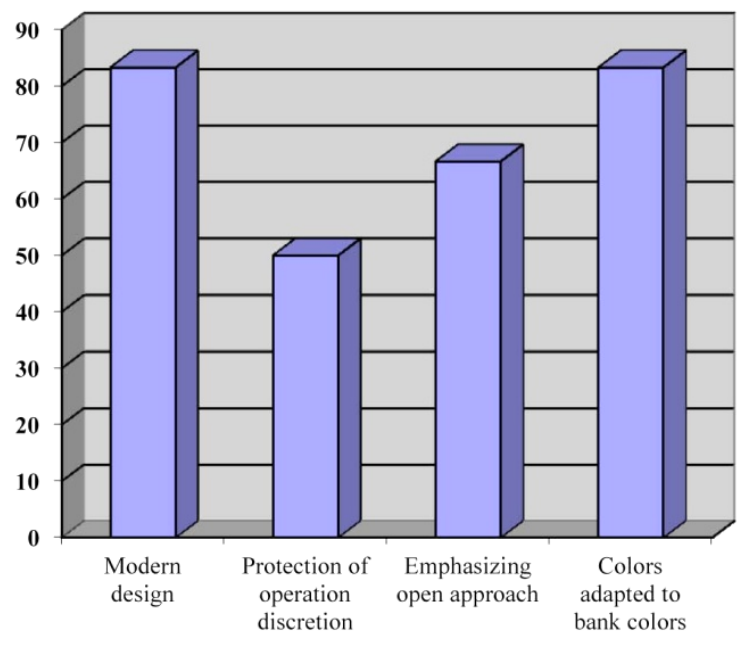

口Bank offices

Figure 4. Architectual solutions in banks (Smajlović 2010)

From the total number of researched banks, $91.66 \%$ have stated that it sponsors different events. Most of the investments are made in sport activities, social functions and art, and the least investments are made to ecology and various television or other programs. It is necessary to emphasize here that from the total number of banks acting as sponsors, $100 \%$ of them sponsor art, $90.9 \%$ sponsor sports, while ecology, social functions and various programs are sponsored by $72.72 \%$ of banks. To communicate with their surroundings, banks use television as a medium the most with $91.66 \%$, printed media with $83.33 \%$, radio $83.33 \%$, and Internet $83.33 \%$, and billboards are used the least with $75 \%$. The relative parts of total significance of a certain medium of communication that banks use to communicate with their surroundings are divided into television, printed media, and billboards, radio, and Internet.

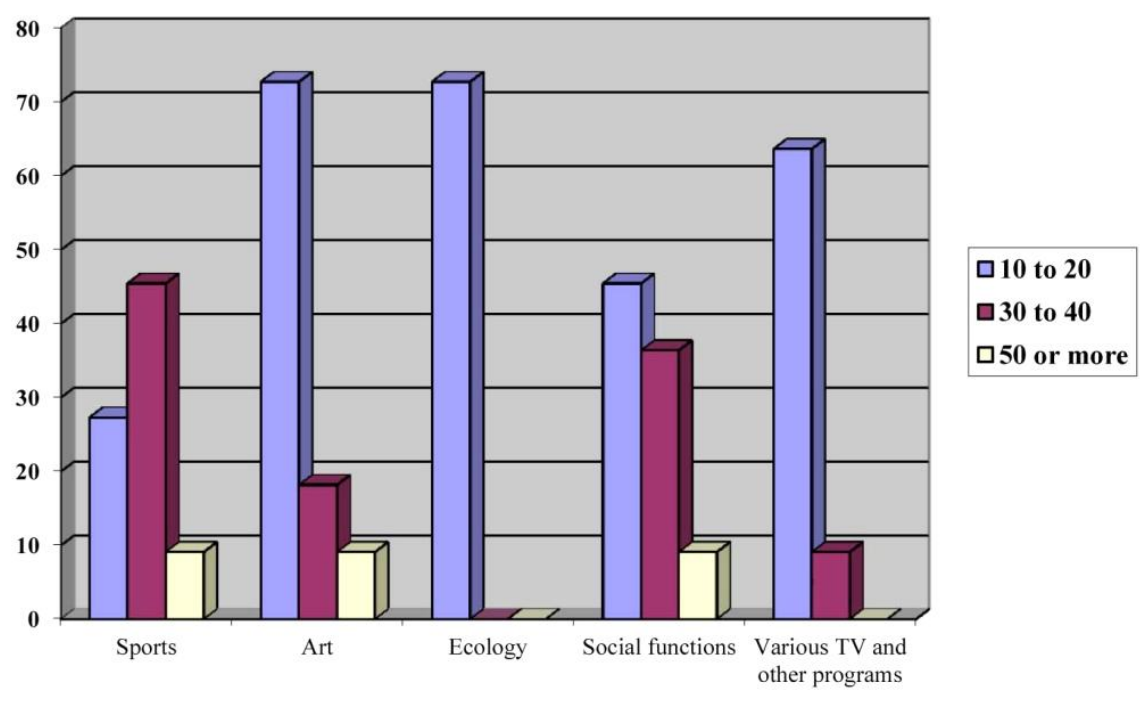

Figure 5. Sponsored events (Smajlović 2010)

When we researched ideal identity we tried to establish if banks have certain marketing strategies, or if they 
monitor operations of their competition and client satisfaction. From the gathered information, we can conclude that $75 \%$ of the researched banks have written documents about their marketing strategies. From the total number of surveyed banks, $83.33 \%$ answered that they monitor client satisfaction, while all banks monitor the operations of their competition.

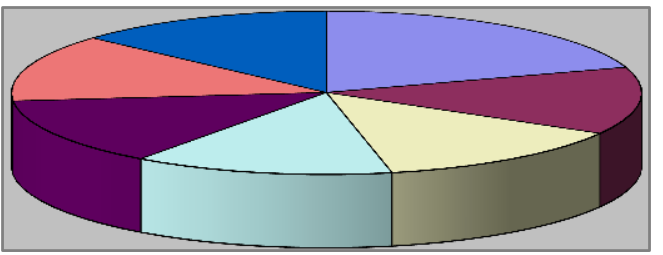

口Secure bank
$\square$ Domestic bank
$\square$ Quality services
$\square$ Stable partner
$\square$ Helps development of social
community
$\square$ Good client relationsip
$\square$ Strongest bank

Figure 6. Desired perception of bank identity (Smajlović 2010)

Desired identity represents a way in which banks desire to be perceived in their surroundings, positioned on market, and how much of the market participation they desire to have. Managers of researched banks noted various characteristics of desired identity, which we grouped into six basic groups: Secure bank 20\%, Domestic bank $13.33 \%$, Bank with quality services $13.33 \%$, Stable and reliable partner $13.33 \%$, Bank that helps development of social community $13.33 \%$, Bank with good client relationship 13.33\%, and Strongest bank $13.33 \%$.
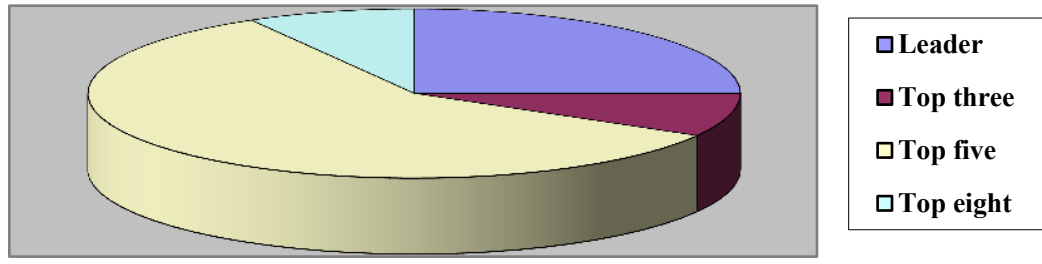

Figure 7. Desired market position (Smajlović 2010)

From the total number of researched banks, $58.33 \%$ expects to be in the top five banks, $25 \%$ expect to be the leader on B\&H market, $8.33 \%$ expects to be in top three, and $8.33 \%$ expects to be in the first eight banks. Banks with largest part (25\%) expect to gain $8 \%$, that is $10 \%$, of market participation. Planned market participation of other banks has been equally divided (12.5\% each) between $5 \%, 15 \%, 20 \%$ and $30 \%$.

\section{Conclusions and Suggestions}

On the basis of research results, it can be concluded that there are significant deviations between actual, communicated, ideal and desired identity of banks on B\&H market, which is a consequence drawn from the inadequacy of systemic approach to managing this phenomenon.

To determine the general conclusion of this paper, we will argument further analysis of gathered results of this research. Data gathered by primary and secondary research show that the largest number of banks in $\mathrm{B} \& \mathrm{H}$ started their operations in the past ten years. Having this in mind, banks are in the process of identity and image creation and cannot rely on tradition of operations in $\mathrm{B} \& \mathrm{H}$, but they rather justify themselves in terms of how long they existed. Another important piece of data in the process of analysis of actual identity is that banks 
significantly went through numerous status changes, such as mergers with one or more banks or takeovers by other banks. Therefore, the largest number of banks, with long tradition of operations in $\mathrm{B} \& \mathrm{H}$, has completely or partially lost their identities. Because of these mentioned events on B\&H market, a significant number of banks have been brought to the very beginning of the identity creation process. With that, banks usually used the following two options: transfer of the built identity from the country of origin in B\&H or combination of identities of foreign banks with strong and recognizable identity of the domestic bank.

If we start off with the fact that all banks offer same or similar type of services, then it is clear that it is very hard to create strong identity and clearly recognizable image that will differentiate them from the competition and position them on the market. The primary research of characteristics, upon which banks differentiate from competition, shows us the numerosity and variability of ways that banks use to show their uniqueness in regards to their competition. Still, a more detailed analysis and comparison of mostly noted characteristics of differentiation, from the first- to the third-ranked, show us that all banks are relying on same characteristics of operation, that is: security, client proximity, assortment quality, staff quality, loyalty, and expeditivity. With that, they almost completely ignore bank brand, which is the most powerful weapon of differentiation from competition and in creation of client loyalty. Relying on same or similar characteristics in the process of differentiation from competition enables banks to create strong identity and recognizable image, since stakeholders cannot recognize their personality nor notice their differences.

The analysis of basic bank operation values and their integrity into their mission and vision has pointed us to notice the lack of basic strategic plans in the process of identity and image creation. Therefore, we can adopt the assumption that banks still have not recognized the significance of this phenomenon nor did they integrate it into their strategic plans, that is, into their mission and vision. Correction of this mishap is necessary in order to establish a systemic approach of identity and image management that would enable their successful creation and maintenance. Good starting assumptions are entrepreneurial organizational structure and team management style that, as data shows, prevail in banks that operate on B\&H market.

In the process of research of ways in which banks communicate their personality to their surrounding, through logo, bank colors, slogans and architecture, we used primary and secondary data. When building their offices and branches, banks take extra attention to the modern design and adapting colors of the exterior and interior to the bank colors. Besides that, banks try to emphasize the open approach, and to protect the discretion of operations. It is necessary to emphasize here that it is very hard to determine the efficiency of communications of bank identity characteristic, since those can be partially recognized in very small number of banks that have published their vision and mission in written documents.

Based on research results, it can be concluded that all banks have recognized the significance of sponsorship in order to communicate their identity. With that, most of the investments go into sports, social functions and art, and least go to ecology and various television and other programs. When communicating with their surrounding, banks use television as medium the most, then printed media, radio and Interned, and billboards are used the least. With that, the relative parts of the total significance of certain media of communication are divided in television, printed media and billboards, and radio and Internet. With that, it is necessary to emphasize that banks still do not use the Internet potential as a media for communication with their surroundings. Namely, bank web-sites are mostly used for advertising and for use of various services (ie, Internet banking), partly used for spreading information about various events that the bank participated in, and not used at all for interactive communication with their surroundings. Based on this fact, it can be noted that banks still use mass communication with surrounding, while communication with targeted segments is much neglected.

Even though, data gathered by primary research shows that $75 \%$ of researched banks in B\&H have written documents on marketing strategies, previously adopted fact that identity and image are not integrated into vision and mission, must not be neglected. If we start from the fact that marketing strategies support realization of banks' strategic plans, then we can take on the attitude that with these phenomena are not paid adequate significance in their creation and realization. With this fact, it is understandable that, even though banks invest significant assets into communication with surroundings, identity characteristics are not explained adequately. Having in mind that creation of strong identity and clearly profiled image requires communication of their characteristics through all instruments and media, then it is clear that this aspect of their management is not adequately solved.

The basic assumption made when creating ideal identity consists of marketing strategies, where constant monitoring of competitor operations and client satisfaction are very necessary. In this way, banks can clearly position themselves on markets and differentiate from competition. Since the existence of marketing strategies 
has been taken into consideration already, we will shortly examine the following two aspects of ideal identity. The research results show that from the total number of surveyed banks, $83.33 \%$ researches client satisfaction, while all banks monitor the operations of their competition.

This data can bring us to a conclusion that banks almost completely fulfill assumptions that are necessary for creation of ideal identity. Nevertheless, they cannot neglect previously noted defects when determining and realizing marketing strategies. With that, it is necessary to conduct a more detailed analysis of goals and methods of client and competition research. Namely, creation of clearly profiled identity, that makes banks differentiate from the competition, requires research of their characteristics, and not only by their clients, but by competition as well. The results gathered through these researches are necessary for correction of ways of communication with surroundings, and for definition of new characteristic or redesign of the existing characteristics. Having in mind that identity and image are neglected in banks' strategic plans, it can be assumed that they are not adequately represented in research processes of banks.

Desired identity represents a way in which banks desire to be perceived in their surroundings, positioned on market, and in what amount they want to participate on markets. Managers of researched banks noted various characteristics of desired identity, and we grouped those into six basic groups: Secure bank, Domestic bank, Bank with quality services, Stable and reliable partner, Bank that helps development of social community, Bank with good client relationship, and Strongest bank. If we compare these results of primary research with the results of secondary research of written bank documents, we can conclude that there are significant deviances. Namely, the basic values that are integrated into bank mission are: improvement of quality of operations, client focus, contribution to economic development of country, while in their vision they defined that they anticipate to: satisfy client needs, become modern banks among the leading banks in B\&H. If we start from the attitude that in visions represent identity characteristics upon which banks want to be recognized in surroundings, then we can adopt an assumption that managers have not recognized the significance of these values or that they are not familiar with them. This brings us to question the adequate communications of these characteristics to the surroundings.

From the total number of researched banks, $58.33 \%$ expects to be in the top five banks, $25 \%$ expect to be the leader on B\&H market, $8.33 \%$ expects to be in top three, and $8.33 \%$ expects to be in the first eight banks. Banks with largest part (25\%) expect to gain $8 \%$, that is $10 \%$, of market participation. On the basis of these results, it can be concluded that not even one bank expects market domination; they rather determine their position in relation to their strongest competition.

On the basis of gathered research results, we can emphasize the following suggestions:

$>$ Banks need to integrate core values of operations into mission and vision so they can correct mistakes in their strategic planning. By implementation of core values of operations, and they are nothing but identity characteristics, banks would realize necessary assumptions of establishing systemic approach to their management. This would enable effective communication of identity characteristics to the internal and external public of the bank.

$>$ Banks need to conduct a research on own and competitor identity. Gathered results from a research on strengths and weaknesses of own identity in relation to competitor identity, as well as on significance of certain operations characteristics for clients on targeted markets, would represent a foundation of creation and implementation of successful positioning strategy. In this way, B\&H banks could overcome the most significant issue when differentiating and positioning, which is a mutual similarity.

$>$ In order to find new identity characteristics, banks can use non-banking institutions and other modern business organizations as benchmarks.

\section{References}

Balmer, J. M. T., \& Greyser, S. A. (2002). Managing the Multiple Identities of the Corporation. California Management Review, 44(3), 72-86. http://dx.doi.org/10.2307/41166133

Balmer, J. M. T., \& Soenen, G. B. (1999). The Acid Test of Corporate Identity Management. Journal of Marketing Management, 15(1-3), 69-92. http://dx.doi.org/10.1362/026725799784870441

Balmer, J. M. T., \& Stotvig, S. (1997). Corporate identity and private banking: a review and case study. International Journal of Bank Marketing, 15(5), 169-184. http://dx.doi.org/10.1108/02652329710175370

Balmer, J. M. T., \& Wilson, A. (1998). Corporate Identity There Is More to It Than Meets the Eye. Int. Studies of Mgt. \& Org. 
Balmer, J. M. T. (1998). Corporate Identity and Advent of Corporate Marketing. Journal of Marketing Management, 14(8), 963-996. http://dx.doi.org/10.1362/026725798784867536

Balmer, J. M. T. (2001a). Corporate Identity, corporate branding and corporate marketing: Seeing throug the fog. European Journal of Marketing, 35(3/4), 248-291. http://dx.doi.org/10.1108/03090560110694763

Balmer, J. M. T. (2001b). From the Pentagon: A new Identity Framework. Corporate Reputation Review, 4, 11-22. http://dx.doi.org/10.1057/palgrave.crr.1540129

Balmer, J. M. T. (2001c). Of Identities Lost and Found. Int. Studies of Mgt. \& Org.

Brown, T. J., Dacin, P. A., Pratt, M. G., \& Whetten, D. A. (2006). Identity, Intended Image, Construed Image, and Reputation: An Interdisciplinary Framework and Suggested Terminology. Journal of the Academy of Marketing Science, 34(2), 99-106. http://dx.doi.org/10.1177/0092070305284969

Cornelissen, J., \& Harris, P. (2001). The Corporate Identnity Metaphor: Perspectives, Problems and Prospect. Journal of Marketing Management, 17(1-2), 49-71. http://dx.doi.org/10.1362/0267257012571456

Fox, T., Balmer, J., \& Wilson, A. (2001). Corporate Identity Management: Applying the ACID Test. A White Paper by CRM (UK) Ltd \& SECTOR Consulting. Retrieved from http://www.sim.hcmut.edu.vn/old/personal/lhhung/WEB-KTHKD/nhom\%2009-Corporate\%20identity\%20 management/ACID01.pdf

Ind, N. (1996). Corporate image. Clio, Beograd.

Kotler. (2001). Marketing Management: Analysis, planning, implementation and control. Mate, Zagreb.

Melewar, T. C., \& Jenkins, E. (2002). Defining the Corporate Identity Construct. Corporate Reputation Review, 5, 76-90. http://dx.doi.org/10.1057/palgrave.crr.1540166

Smajlović, E. (2010). Strategic causality identity and image banks in operation to adapt to changes in the banking market. Unpublished doctoral dissertation, Faculty of Economics, University of Tuzla, Tuzla, Bosnia and Herzegovina.

\section{Notes}

Note 1. Today, the most influential is the corporate identity mix, developed by Birkigt and Stadler (1986). The components of their mix are: corporate personality, behavior, communication and symbolism (Balmer 2002).

Note 2. In the enlightenment of bank identity, other similar approaches can be used, such as the four key aspects of organization: 1 . Who are we as a bank? 2. What does a bank want others to think of it? 3. What does a bank believe that others think of it? 4. What do stakeholders really think of the bank? (adapted from: Brown, Dacin, Pratt, Whetten (2006), pg. 100).

\section{Copyrights}

Copyright for this article is retained by the author(s), with first publication rights granted to the journal.

This is an open-access article distributed under the terms and conditions of the Creative Commons Attribution license (http://creativecommons.org/licenses/by/3.0/). 